\title{
Noch lang kein Alltag in Sicht!
}

Fast zwei Jahre nach der Neugründung konnten sehr viele Routinen etabliert werden, der Alltag ist jedoch noch weit entfernt. Und immer noch bleibt dabei ein ganz entscheidender Punkt: das Personal.

\section{Dr. Philipp F. Gebhardt // \\ BISS45 Kieferorthopädie Berlin, www.biss45.de \\ Dr. Gebhardt berichtet seit 2009 in jeder \\ Ausgabe über seinen Weg vom abge- \\ schlossenen Studium zum jungen Zahnarzt.

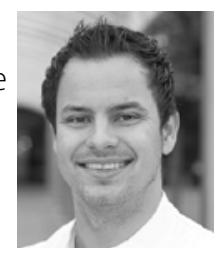

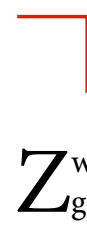

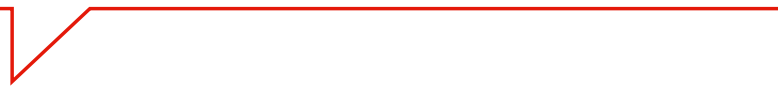

7 war hat sich der anfängliche Personalmangel inzwischen gelegt und mein Team ist mittlerweile auf über zehn Mitarbeiter angewachsen. Jedoch verlief dieser Prozess nicht ganz reibungslos. Ich hatte zwar versucht, keine Mitarbeiter zu beschäftigen, die verwandt oder eng befreundet waren, um ein inkonstantes Kräfteverhältnis im Team zu vermeiden. Aufgrund der zähen Suche musste ich in diesem Punkt jedoch Kompromisse eingehen. Naheliegend ist hier oft, dass die Mitarbeiter, wie in meinem Fall, auch vorher schon zusammen in einer Praxis gearbeitet haben. Für versierte und qualifizierte Helferinnen ist dieser Aspekt gegebenenfalls sogar ein Vorteil, da es den Rest des Teams motivieren kann.

Bei mir kam es jedoch zu einer Spaltung des Teams, die sich aufgrund der zu geringen Fachkenntnisse der einen Hälfte des
Personals auch trotz eines Businesscoaches und regelmäßiger Einzel- und Teamgespräche nicht nachhaltig beheben ließ. Aus diesem Grund musste ich mich sehr kurzfristig von vier Angestellten trennen. Ich hatte zur Sicherheit zwar schon einige Bewerber als Backup zum Gespräch eingeladen. Doch selbst nach einer Zusage gibt es immer eine gewisse Latenzzeit, bis die neuen Kollegen ihren ersten Arbeitstag haben und später vollständig eingearbeitet sind. Nachtschichten standen für mich in dieser Phase wieder an der Tagesordnung, und auch für den Rest des Teams war diese Zeit extrem anspruchsvoll. Durch die vorhandene Perspektive an neuen Mitarbeitern konnten sich glücklicherweise alle zu diversen Überstunden motivieren. Ein positiver Nebeneffekt war, dass alle Mitarbeiter nach dieser Erfahrung umso enger zusammen halten und sich den Rücken stärken.

Fazit: Es ist sehr sinnvoll, Bewerbungen auch bei einer augenscheinlich guten Personalsituation im Auge zu behalten und nicht unbeantwortet wegzuwerfen. Ich hatte anfangs versucht, Überkapazitäten beim Personal zu vermeiden. Der Grund hierfür war die Gefahr, dass sich die Angestellten zu schnell an eine geringere Arbeitsbelastung gewöhnen. Gerade bei einer Neugründung sollte man jedoch davon ausgehen, dass selbst bei Arbeitsbedingungen, die man als ideal einstuft, Mitarbeiter kurzfristig ausscheiden können. Am Ende musste ich auch erst lernen, dass einige Helferinnen eine wachsende Praxis nicht als Chance sehen, sondern eher als Risiko und Stressfaktor.

\section{Impressum}

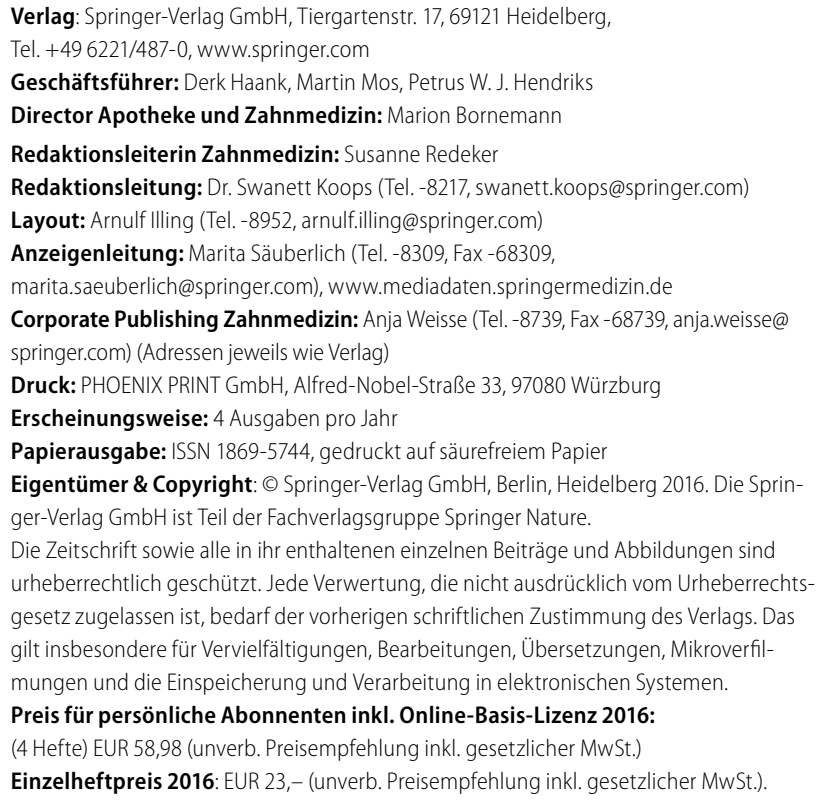

Für Studierende und für Ärzte in der Facharztausbildung ermäßigt sich 2016 der Bezugspreis auf jährlich EUR 35,39 (unverb. Preisempfehlung inkl. gesetzlicher MwSt., Nachweis über Studium/Ausbildung erforderlich). Institutspreis inkl. Online-Basis-Lizenz 2016: (4 Hefte) EUR 199,09 (unverb. Preisempfehlung inkl. gesetzlicher MwSt.). Der Bezugspreis ist im Voraus zu zahlen. Das Abonnement kann bis 30 Tage vor Ende des Bezugszeitraums gekündigt werden.

Allgemeiner Hinweis zur gesetzlichen Mehrwertsteuer: Gedruckte Zeitschriften unterliegen grundsätzlich dem ermäßigten Steuersatz von 7\%, digitale Produkte (wie z.B. die Online-Version einer Zeitschrift) hingegen dem allgemeinen Steuersatz von 19\%. Die detaillierteAufteilung der einzelnen Mehrwertsteuer-Beträge entnehmen Sie bitte Ihrer Rechnung.

Bestellungen oder Rückfragen nimmt jede Buchhandlung oder der Verlag entgegen. Springer Customer Service Center GmbH, Haberstr. 7, 69126 Heidelberg, Tel. +49 6221/345-4303, Fax +496221/345-4229, Leserservice@springer.com (Mo.-Fr. 8.00 Uhr bis $18.00 \mathrm{Uhr}$ )

Autoren können unter bestimmten Voraussetzungen an der Ausschüttung der Bibliotheks- und Fotokopietantiemen teilnehmen. Einzelheiten bei VG WORT, Abt. Wissenschaft, Goethestr. 49, 80336 München.

Angaben über Dosierungsanweisungen und Applikationsformen sind anhand anderer Literaturstellen oder der Packungsbeilage auf ihre Richtigkeit zu überprüfen. Der Verlag übernimmt keine Gewähr.

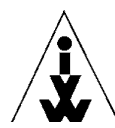

